\title{
A INTERFACE INSTITUCIONAL ENTRE A ANS E O PODER JUDICIÁRIO: ANÁLISE DE ACÓRDÃOS SOBRE A COBERTURA DE EMERGÊNCIAS MÉDICAS EM PLANOS DE SAÚDE
}

The institutional interface between Brazilian Regulatory Agency for Private Health Insurance and Judiciary: analysis of judicial cases about medical care for emergencies in healthcare plans

${ }^{1}$ Fundação Getúlio Vargas. Rio de Janeiro/RJ, Brasil.

Correspondência: Bruno Araujo Ramalho. E-mail: brunrama@hotmail.com.

Recebido em: 20/03/2015. Revisado em: 08/06/2015. Aprovado em: 10/06/2015. 


\section{RESUMO}

O presente artigo dedica-se a analisar o controle judicial da norma regulatória atualmente adotada pela Agência Nacional de Saúde Suplementar (ANS) para a cobertura de urgências e emergências médicas em planos de assistência à saúde. Para tanto, foi feita uma revisão jurisprudencial de acórdãos dos tribunais de São Paulo, Rio de Janeiro e Minas Gerais que versavam sobre o tema e, ao final, verificou-se que a norma regulatória tem sido considerada ilegal pela maioria dos integrantes desses tribunais (com exceção de uma Câmara Cível específica do Tribunal de São Paulo). Os resultados da revisão jurisprudencial foram discutidos tomando-se por base o grau de vinculação à juridicidade e destacando-se os problemas epistêmicos existentes atualmente para a caracterização de uma urgência médica, bem como para a definição do alcance a ser dado na cobertura desta natureza. Na conclusão da pesquisa, demonstrou-se haver a necessidade de um melhor paradigma regulatório e de uma harmoniosa interface institucional entre a agência reguladora e o Poder Judiciário.

Palavras-Chave: Emergência Médica; Plano de Saúde; Revisão judicial.

\section{ABSTRACT}

This article makes a descriptive analysis of judicial review of the regulations adopted by the Brazilian National Regulatory Agency for Private Health Insurance and Plans (ANS - in Portuguese) in relation to cases involving emergency coverage to health care plans users. Thus, it was made a review of judgments from courts of the states of São Paulo, Rio de Janeiro and Minas Gerais that focused on this topic and, as a result, it was found that the regulatory standard has been declared illegal by most members of these courts (except for a specific section in the Court of São Paulo). The results were discussed, based on the levels of judicial intervention and highlighting epistemic problems for the characterization of a medical emergency, as well problems to define its limits. As a conclusion, it was shown there is a clear need for a better regulatory standards and a harmonious institutional interface between the regulatory agency and the judiciary.

Keywords: Emergency Care; Healthcare Plans; Judicial Review. 


\section{Introdução}

Ainda que a Constituição Federal de 1988 (CF/88) garanta a livre iniciativa para que a saúde suplementar seja explorada pela iniciativa privada ${ }^{1}$, este setor atende a uma função de profundo envolvimento estatal ${ }^{2}$, uma vez inserido dentro da política nacional de saúde. Ademais, embora os planos e seguros de assistência à saúde sejam regidos por um instrumento de direito privado, a necessária garantia de qualidade e dos cuidados à saúde torna inexorável a observância de sua função social ${ }^{3}$.

Nessa toada, no intuito de "[...] proteger os consumidores de eventuais abusos que venham ser contra eles praticados", o marco regulatório da saúde suplementar trouxe uma série de parâmetros de cobertura a ser observada pelas operadoras de planos privados de assistência à saúde.

Como se trata de um produto a ser usufruído mediante pagamento, a legislação também criou prazos mínimos de carência para desestimular comportamentos oportunistas - tais como seleção adversa, que ocorre em decorrência de uma informação privilegiada que o beneficiário sabe sobre o seu próprio risco de morbidade.

$\mathrm{Na}$ correlação entre as coberturas e seus respectivos prazos de carência, a Lei Federal n. 9.656/1998 (Lei dos Planos de Saúde), em seu artigo 35-C, deu especial destaque às hipóteses de urgência e emergência, nas quais o atendimento deve ser garantido logo após 24 horas da contratação $\left(\operatorname{artigo} 12^{6}\right.$ ). Tal condição deve-se ao imediatismo e ao maior grau de incerteza inerentes à natureza desses sinistros.

Em nível infralegal, a cobertura para urgências e emergências nos planos de saúde foi regulamentada pela Resolução n. 13/1998 ${ }^{7}$ do Conselho Nacional

\footnotetext{
1“Art. 199. A assistência à saúde é livre à iniciativa privada”. BRASIL. Constituição da República Federativa do Brasil de 1988, de 05 de outubro de 1988. Disponivel em: <http://http://www.planalto.gov.br/ccivil_03/ constituicao/constituicaocompilado.htm>. Acesso em: 28 abr. 2016.

${ }^{2}$ SCHULMAN, Gabriel. Planos de saúde: saúde e contrato na contemporaneidade. Rio de Janeiro: Renovar, 2009. p. 306. ${ }^{3}$ FIGUEIREDO, Leonardo Vizeu. Curso de direito em saúde suplementar: manual jurídico de planos e seguros de saúde. São Paulo: MP Ed., 2006. p. 119.

${ }^{4}$ Trecho extraído da exposição de motivos da Medida Provisória n. 2.177-44, de 24 de Agosto de 2001, que alterou substancialmente o teor da Lei Federal n. 9.656/1998. Diário da Câmara dos Deputados, de 09/10/2001, p. 585. Disponível em: <http://imagem.camara.gov.br/dc_20.asp?selCodColecaoCsv=J\&Dat ain=09/10/2001\&txpagina=20778\&altura=700\&largura=800>. Acesso em: 20 jan. 2016.

${ }^{5}$ BRASIL. Lei Federal n. 9.656, de 03 de junho de 1998. Dispõe sobre os planos e seguros privados de assistência à saúde. Disponível em: <http://www.planalto.gov.br/ccivil_03/leis/L9656compilado.htm>. Acesso em: 28 abr. 2016.

“'Art. 12. São facultadas a oferta, a contratação e a vigência dos produtos de que tratam o inciso l e o $\S 1^{\circ}$ do art. $1^{\circ}$ desta Lei, nas segmentações previstas nos incisos I a IV deste artigo, respeitadas as respectivas amplitudes de cobertura definidas no plano-referência de que trata o art. 10, segundo as seguintes exigências mínimas: [...] V - quando fixar períodos de carência: a) prazo máximo de trezentos dias para partos a termo; b) prazo máximo de cento e oitenta dias para os demais casos; c) prazo máximo de vinte e quatro horas para a cobertura dos casos de urgência e emergência". BRASIL. Lei Federal n. 9.656, de 03 de junho de 1998, cit.

${ }^{7}$ CONSELHO NACIONAL DE SAÚDE SUPLEMENTAR. Resolução n. 13, de 03 de novembro de 1998. Dispõe sobre a cobertura do atendimento nos casos de urgência e emergência. Disponível em: <http://www.abramge.com.br/portal/index.php?option=com_simplefilemanager\&view=simplefilemanagers\&layout=list\&cat id=100\&showDate=0\&showNew=0\&showSize=0\&orderBy=a.file_created\&order=DESC\&Itemid=293\&lang $=$ pt-BR>. Acesso em: 28 abr. 2016.
} 
de Saúde Suplementar (CONSU), ocasião em que ficaram definidas uma série de condições, exceções e delimitações quanto à operacionalização desse direito legalmente previsto. Essa norma ainda permanece em vigor e foi incorporada ao ordenamento jurídico regulatório adotado pela Agência Nacional de Saúde Suplementar (ANS), conforme pode ser atestado em consulta ao sítio eletrônico desta autarquia ${ }^{8}$.

Ocorre que a Resolução CONSU n. 13/1998, ao regulamentar o comando trazido pela norma legal, preconizou um formato em que a prestação da assistência às urgências e emergências limita-se aos procedimentos de manutenção da vida executados na segmentação ambulatorial. Em outras palavras, definiu que a internação hospitalar não é parte integrante em qualquer atendimento de emergência, mas sim um desdobramento posterior àquele pronto atendimento fornecido em nível ambulatorial.

Desta feita, a lógica adotada na operacionalização do conceito legal entendeu válida a imposição de carência para internações hospitalares (180 dias) para a maior parte dos atendimentos de urgência e emergência que venham a necessitar de posterior transferência para leito hospitalar (após as etapas ambulatoriais do pronto atendimento). De acordo com a norma regulatória, no transcurso das 12 primeiras horas, caso o beneficiário não tenha direito contratual à internação hospitalar, considera-se lícito que a operadora indique sua remoção para um leito do Sistema Único de Saúde (SUS) ou encerre sua responsabilidade quanto ao custeio da assistência no leito da rede privada.

Em decorrência da delimitação restritiva trazida pela Resolução CONSU n. 13/1998, a validade desta regra tem sido contestada no bojo de processos judiciais, o que acaba gerando um ponto-gatilho para judicialização de vários casos idênticos.

Em dissertação de mestrado elaborada por Rodrigo M. Ribeiro ${ }^{9}$, a aplicabilidade da Resolução CONSU n. 13/1998 em demandas judiciais foi examinada com profundidade à luz do Direito Administrativo. Não obstante, a abordagem foi preponderantemente argumentativa e não se valeu de um recorte empírico mais exaustivo e transversal. A mesma observação pode ser atribuída à contribuição de Bernardo F. Dahinten ${ }^{10}$, que discutiu o tema à luz do Direito Civil e Direito do Consumidor.

Vale ressaltar que o problema envolvendo emergências médicas em planos de saúde também foi descrito em relevantes contribuições empíricas sobre a

\footnotetext{
${ }^{8}$ AGÊNCIA NACIONAL DE SAÚDE SUPLEMENTAR (ANS). Busca de Legislação. Disponível em: http://www.ans. gov.br/legislacao/busca-de-legislacao. Acesso em: 10 jan. 2015.

${ }^{9}$ RIBEIRO, Rodrigo M. O controle judicial sobre as cláusulas de carência nos planos de saúde. 2009. Dissertação (Mestrado em Direito) - Faculdade de Direito da Universidade Candido Mendes, 2009.

${ }^{10}$ DAHINTEN, Bernardo F. Planos de saúde e a proteção dos consumidores: a problemática dos casos de urgência/emergência. Revista Síntese Direito Empresarial, v. 30, p. 131-171, 2013.
} 
judicialização na saúde suplementar ${ }^{11},{ }^{12},{ }^{13},{ }^{14}$, embora isso tenha sido feito em conjunto com vários outros assuntos - o que acabou limitando a profundidade exploratória quanto ao tema em questão.

Nesse sentido, o presente trabalho presta-se a executar uma análise descritiva exclusivamente dedicada ao exame judicial da norma regulatória aplicável em emergências médicas (Resolução CONSU n. 13/1998), com vistas a identificar as diferentes linhas argumentativas que têm sido adotadas judicialmente para a definição dos litígios sobre o tema.

A partir desta seção introdutória, o artigo será dividido em três partes. Inicialmente, serão destacadas algumas questões importantes sobre as emergências médicas em planos de saúde. Em seguida, serão descritos a metodologia e os resultados da investigação empírica sobre a jurisprudência de três importantes estados do Brasil: São Paulo, Rio de Janeiro e Minas Gerais ${ }^{15}$, acerca do tema. Na última parte, os resultados serão comparados entre si e será feita uma discussão sobre a fundamentação decisória desses tribunais e sobre o problema decorrente da assimetria entre a regulação e o entendimento do Poder Judiciário nos casos concretos examinados.

\section{Uma visão geral sobre o problema envolvendo emergências médicas em planos de saúde}

A regulação da saúde suplementar decorre do marco regulatório dos planos de saúde - destacando-se, aqui, a Lei n. 9.656/1998 e a Lei Federal n. 9.961/2000 ${ }^{16}$ (Lei de Criação da ANS). A partir desses standards, uma série de outras regras são estabelecidas pelo regulador e, com efeito, criam-se direitos e obrigações. Nesse sentido, cabe ao julgador a difícil tarefa de conhecer quais são esses instrumentos infralegais e conceder-lhes a operabilidade devida. Como destacado pela jurista Sueli G. Dallari,

\footnotetext{
${ }^{11}$ SCHEFFER, Mário. Os planos de saúde nos tribunais: uma análise das ações judiciais movidas por clientes de planos de saúde, relacionadas à negação de coberturas assistenciais no Estado de São Paulo. 2006. Dissertação (Mestrado) - Faculdade de Medicina, Universidade de São Paulo, São Paulo, 2006.

${ }^{12}$ SOUZA, M.H.S.C. et al. A intervenção do Poder Judiciário no setor de saúde suplementar - tutelas antecipadas como instrumento de garantia da assistência à saúde no Brasil. Divulgação em Saúde para Debate, Rio de Janeiro, n. 37, p. 44-60, jan. 2007. Disponível em: <http://abresbrasil.org.br/sites/default/files/ poder_judiciario_bahia.pdf>. Acesso: 01 mar. 2016.

${ }^{13}$ ALVES, Danielle C.; BAHIA, Lígia; BARROSO, André F. O papel da Justiça nos planos e seguros de saúde no Brasil. Cad. Saúde Pública, Rio de Janeiro, 25, n. 2, p. 279-290, fev. 2009. Disponível em: <http://www. scielo.br/pdf/csp/v25n2/06.pdf>. http://dx.doi.org/10.1590/S0102-311X2009000200006.

${ }^{14}$ TRETTEL, Daniela B. Planos de saúde na Justiça: o direito à saúde está sendo efetivado? Estudo do posicionamento dos Tribunais Superiores na análise dos conflitos entre usuários e operadoras de planos de saúde. 2009. Dissertação (Mestrado) - Faculdade de Direito, Universidade de São Paulo, São Paulo, 2009.

${ }^{15} \mathrm{~A}$ razão para a escolha desses três estados será explicada adiante.

${ }^{16}$ BRASIL. Lei Federal n. 9.961, de 28 de janeiro de 2000. Cria a Agência Nacional de Saúde Suplementar - ANS e dá outras providências.Disponível em: <http://www.planalto.gov.br/ccivil_03/leis/L9961.htm>. Acesso em: 28 abr. 2016.
} 
[...] é preciso, portanto, que o julgador seja capaz de identificar não apenas os argumentos que têm como base atos legislativos em sentido próprio, mas também aqueles que se originam no poder normativo da Administração, e ainda os que têm fundamento no poder normativo propriamente público, derivado da efetiva participação das pessoas na definição e na realização do direito à saúde ${ }^{17}$.

Não obstante, a própria disponibilidade dessas regras no ordenamento positivo pode se apresentar de forma incoerente e dificultar a definição dos parâmetros epistêmicos a serem seguidos. Este, como será visto a partir de agora, parece ser um dos problemas relacionados às coberturas de emergências médicas na saúde suplementar.

No âmbito legal, a cobertura de urgências e emergências em planos de saúde é definida pelo artigo 35-C da Lei Federal n. 9.656/1998, abaixo transcrito:

Art. 35-C. É obrigatória a cobertura do atendimento nos casos: I - de emergência, como tal definidos os que implicarem risco imediato de vida ou de lesões irreparáveis para o paciente, caracterizado em declaração do médico assistente;

II - de urgência, assim entendidos os resultantes de acidentes pessoais ou de complicações no processo gestacional;

III - de planejamento familiar.

Parágrafo único. A ANS fará publicar normas regulamentares para o disposto neste artigo, observados os termos de adaptação previstos no art. $35^{18}$.

Não obstante, além da previsão legal acima exposta, os conceitos de "urgência" e "emergência" também são operacionalizados por duas normas infralegais de diferentes entidades: uma voltada para o exercício da medicina (Resolução n. $1.451 / 1995^{19}$ do Conselho Federal de Medicina - CFM) e a outra voltada para o setor de planos de saúde: CONSU n. 13/1998.

Quando feita uma leitura comparativa entre as normas existentes, percebe-se haver um conflito de definições quanto ao padrão técnico para cada um dos conceitos em análise, conforme sistematizado no Quadro 1.

\footnotetext{
${ }^{17}$ DALLARI, Sueli G. Aspectos particulares da chamada judicialização da saúde. Revista de Direito Sanitário, São Paulo, v. 14, n. 1, p. 80, mar./jun. 2013. Disponível em: <http://www.revistas.usp.br/rdisan/article/ view/56624/59641>. http://dx.doi.org/10.11606/issn.2316-9044.v14i1p77-81.

${ }^{18}$ BRASIL. Lei Federal n. 9.656, de 03 de junho de 1998, cit.

${ }^{19}$ CONSELHO FEDERAL DE MEDICINA. Resolução n. 1.451, de 10 de março de 1995. Disponível em: <http:// www.portalmedico.org.br/resolucoes/cfm/1995/1451_1995.htm>. Acesso em: 28 abr. 2016.
} 
Quadro 1. Caracterização dos conceitos de "urgência" e "emergência”, a depender do instrumento normativo.

\begin{tabular}{|c|c|c|}
\hline Norma & Conceito de Urgência & Conceito de Emergência \\
\hline CFM n. 1.451/1995 & $\begin{array}{l}\text { Artigo } 1^{\circ}[. . .] \text { Parágrafo Primeiro } \\
\text { - Define-se por URGÊNCIA a } \\
\text { ocorrência imprevista de agravo à } \\
\text { saúde com ou sem risco potencial } \\
\text { de vida, cujo portador necessita } \\
\text { de assistência médica imediata. }\end{array}$ & $\begin{array}{l}\text { Artigo } 1^{\circ}[. . .] \text { Parágrafo Segundo - Define- } \\
\text { se por EMERGÊNCIA a constatação } \\
\text { médica de condições de agravo à saúde } \\
\text { que impliquem em risco iminente de vida } \\
\text { ou sofrimento intenso, exigindo, portanto, } \\
\text { tratamento médico imediato. }\end{array}$ \\
\hline CONSU n. 13/1998 & $\begin{array}{l}\text { No tocante aos conceitos, a } \\
\text { norma se remete à letra da Lei } \\
\text { Federal n. } 9.656 / 1998^{20} \text {. }\end{array}$ & $\begin{array}{l}\text { No tocante aos conceitos, a norma } \\
\text { se remete à letra da Lei Federal n. } \\
9.656 / 1998 \text {. }\end{array}$ \\
\hline $\begin{array}{l}\text { Lei Federal } \\
\text { n. } 9.656 / 1998\end{array}$ & $\begin{array}{l}\text { Artigo35-C. É obrigatória a } \\
\text { cobertura do atendimento nos } \\
\text { casos: }[\ldots] \\
\text { II - de urgência, assim entendidos } \\
\text { os resultantes de acidentes } \\
\text { pessoais ou de complicações no } \\
\text { processo gestacional. }\end{array}$ & $\begin{array}{l}\text { Artigo 35-C. É obrigatória a cobertura } \\
\text { do atendimento nos casos: } \\
\text { I- de emergência, como tal definidos } \\
\text { os que implicarem risco imediato de } \\
\text { vida ou de lesões irreparáveis para o } \\
\text { paciente, caracterizado em declaração } \\
\text { do médico assistente. }\end{array}$ \\
\hline
\end{tabular}

Fonte: Elaboração própria.

Verifica-se que, no tocante ao conceito de "emergência", as diferentes normas convergem com relação ao elemento "risco imediato de vida", mas divergem com relação aos atributos de "risco de sofrimento intenso" (Resolução CFM) e "risco de lesão irreparável" (Resolução CONSU e Lei Federal). Igual imprecisão ocorre com a disciplina do conceito de "urgência": a resolução do CFM condiciona a hipótese a uma situação de "agravo imprevisto na condição de saúde" (com ou sem risco de vida), enquanto a Resolução CONSU delimita duas ocorrências bem específicas: "acidentes pessoais" e "complicações no processo gestacional".

Não bastasse a falta de simetria entre os dois referenciais regulatórios sobrepostos, outra relevante fonte de integração conceitual que não pode ser ignorada nesses casos é aquela que decorre de protocolos internacionais de estratificação de risco que são eventualmente adotados pelos hospitais brasileiros, haja vista a inexistência de um protocolo único para elegibilidade de urgências e emergências no Brasil.

Nesse sentido, além do Protocolo de Manchester - triagem que adota parâmetros como "muito urgente" e "pouco urgente" -, existem vários outros standards de estratificação de risco, cada qual com suas particularidades e categorizações, tais como a escala

20 “Art. $1^{\circ}$ A cobertura dos procedimentos de emergência e urgência de que trata o art.35D, da Lei n 9.656/98, que implicar em risco imediato de vida ou de lesões irreparáveis para o paciente, incluindo os resultantes de acidentes pessoais ou de complicações no processo gestacional, deverá reger-se pela garantia da atenção e atuação no sentido da preservação da vida, órgãos e funções, variando, a partir daí, de acordo com a segmentação de cobertura a qual o contrato esteja adscrito". BRASIL. Lei Federal n. 9.656, de 03 de junho de 1998, cit. 
norte-americana - Emergency Severity Index (ESI) -, a escala australiana - Australian Triage Scale (ATS) - e o protocolo canadense - Canadian Triage Acuity Scale (CTAS) ${ }^{21}$.

Isto posto, podemos concluir que os referenciais trazidos pela legislação regulatória, pelo CFM e pelos protocolos clínicos internacionais simplesmente não "conversam" entre si, porquanto não existe um consenso semântico para a delimitação técnica do que pode ser considerado um "atendimento emergencial". Destarte, a idealização de uma rotina operacionalmente viável já encontra obstáculos em decorrência da própria incoerência técnica ora descrita.

Ademais, quando analisamos apenas o parâmetro da Lei Federal n. 9.656/1998, o enquadramento de uma "emergência" depende de atributos cuja inferência secundária é de difícil delimitação fática ("risco imediato de vida” e "lesão irreparável ao paciente"), haja vista que a flexibilidade na adequação desses atributos a diferentes estados de coisas torna difícil a distinção entre os casos que estão "dentro" e aqueles que estão "fora" da regra. Com efeito, o critério adotado pelo médico para a elegibilidade daquilo que é ou não é uma "emergência" implica em uma inevitável dependência dos critérios daquele profissional responsável pelo atendimento. Como bem aponta Angélica L. Carlini:“[...] o juiz trabalha com o conceito de saúde e de tratamento que lhe é fornecido pelo médico que assiste o paciente e que, por seu relatório, fundamenta tecnicamente o pedido" ${ }^{22}$. Desta feita, [...] contrariar o parecer técnico do médico é inviável para os magistrados, seja pela complexidade do conhecimento, seja pela exclusividade que se atribui ao médico para tratar dos assuntos referentes à saúde e sua manutenção"23.

Assim, acrescenta-se ao problema da incoerência normativa um complicador: os inevitáveis conflitos de enquadramento técnico e a assimetria de informação existente entre as partes envolvidas (médico e paciente; médico e operadora de planos de saúde).

Como parte substancial dos planos de saúde fica submetida à limitação de cobertura para as 12 primeiras horas quando não cumprida a carência de 180 dias para internações hospitalares, a tutela jurisdicional revela-se como um atalho encontrado pelos beneficiários para se protegerem de tais condições. Os resultados obtidos pela revisão jurisprudencial serão úteis para ilustrar como tal questão vem sendo definida pelos tribunais estudados.

\section{Materiais e métodos}

Para a busca dos tribunais inferiores mais relevantes, levou-se em conta o levantamento da Agência Nacional de Saúde Suplementar (ANS) sobre a distribuição

\footnotetext{
${ }^{21}$ SOUZA, C.C. et al. Classificação de risco em pronto-socorro: concordância entre um protocolo institucional brasileiro e Manchester. Rev. Latino-Am. Enfermagem [Internet], v. 19, n. 1, jan./fev 2011. Disponível em: <http:// www.eerp.usp.br/rlae>. Acesso em: 13 abr. 2015. http://dx.doi.org/10.1590/S0104-11692011000100005. ${ }^{22}$ CARLINI. Angélica Lucia. Judicialização da Saúde Pública no Brasil. In: CARNEIRO, Luiz Augusto (Coord.). Planos de saúde: aspectos jurídicos e econômicos. Rio de Janeiro: Forense, 2012. p. 19.

${ }^{23}$ Id. Ibid. p. 21.
} 
de beneficiários pelo território brasileiro, no qual ficou registrado que $60,79 \%$ de todos os beneficiários do Brasil se concentram nos estados de São Paulo, Rio de Janeiro e Minas Gerais ${ }^{24}$. Sendo assim, o posicionamento do Poder Judiciário a que se refere esta pesquisa limita-se àquele observado nos tribunais destes três estados.

Para verificar a jurisprudência de cada um desses tribunais, foi realizada uma busca em seus respectivos sítios eletrônicos na data de 12 de fevereiro de 2015, limitando-se os resultados até esta data. Como o escopo da investigação foi avaliar o controle judicial especificamente direcionado à norma regulatória sobre urgências e emergências (Resolução CONSU n. 13/1998), optou-se pela escolha combinada das palavras-chave "CONSU" e "13".

Essa opção metodológica buscou minimizar sobreposições que certamente seriam observadas caso o critério de busca associasse os termos "plano de saúde" e "seguro saúde" com as palavras-chave "emergência" e "urgência". Isso porque, ainda que os termos estivessem relacionados a emergências em planos de saúde, restaria prejudicada a análise de um ponto crucial que estrutura a proposta deste artigo: a aplicabilidade da norma regulatória para o caso concreto, uma vez que o critério de busca seria permissivo à presença de acórdãos que não enfrentaram essa questão.

Isto posto, buscou-se obter um resultado amostral que fosse bastante sensível ao objeto de análise e que, desta forma, permitisse maior homogeneidade para a comparabilidade entre as diferentes linhas argumentativas. Os resultados estão descritos na Tabela 1.

Tabela 1. Resultados para a pesquisa de Jurisprudência.

\begin{tabular}{lll}
\hline Tribunal & Palavra-Chave & Resultados obtidos \\
\hline Tribunal de Justiça do Estado de São Paulo (TJ-SP) & “Consu 13” & 96 acórdãos \\
Tribunal de Justiça do Estado do Rio de Janeiro (TJ-RJ) ${ }^{26}$ & “Consu 13” & 63 acórdãos \\
Tribunal de Justiça do Estado de Minas Gerais (TJ-MG) ${ }^{27}$ & Consu e 13 & 27 acórdãos \\
\hline
\end{tabular}

Da base de resultados listados na tabela acima, fez-se um agrupamento dos acórdãos em uma planilha para cada tribunal e foi determinado um duplo critério de classificação: "Com Análise do Mérito" e "Sem Análise do Mérito"28.

\footnotetext{
${ }^{24}$ Juntos, os três estados reúnem 30.961 .775 beneficiários do total de 50.930 .043 beneficiários de planos de assistência médica no Brasil, conforme a edição de setembro de 2014 do Caderno de Informações da Agência Nacional de Saúde Suplementar. AGÊNCIA NACIONAL DE SAÚDE SUPLEMENTAR - ANS (Brasil). Caderno de Informação de Saúde Suplementar: beneficiários, operadoras e planos. Agência Nacional de Saúde Suplementar, set. 2014.

${ }^{25}$ SUPERIOR TRIBUNAL DE JUSTIÇA - STJ. Disponível em: <http://www.stj.jus.br>. Caminho da consulta: "Advogado" > "Consulta de Jurisprudência" > "Acórdãos".

${ }^{26}$ Idem.

${ }^{27}$ Idem.

${ }^{28}$ Vale ressaltar que, embora sob a mesma denominação, essa tipologia não se confunde com aquela prevista pelo Direito Processual Civil.
} 
Agruparam-se na categoria "Com Análise do Mérito" aqueles casos em que o julgado apreciou aspectos de fato e de direito relacionados à cobertura pleiteada. "Sem Análise do Mérito" foram considerados os demais acórdãos em que a decisão não examina a aplicabilidade da Resolução CONSU ou se limita a examinar questões formais ou fora do escopo deste estudo, tais como: julgados sobre reajuste; julgados em que a CONSU n. 13/1998 não é aplicável ao objeto da lide e é citada circunstancialmente ou no bojo de ementas transcritas no acórdão; discussão apenas de aspectos processuais (cabimento da antecipação de tutela, substituição do autor após falecimento etc.).

Cada julgado foi submetido a uma leitura de seu inteiro teor, de onde foi possível sistematizar diferentes informações em uma planilha (cada qual em uma coluna) a partir das seguintes regras de preenchimento:

(a) Data de Publicação do Acórdão: Data no formato "dd/mm/aaaa".

(b) Condição médica relacionada: denominação exata dada pelo acórdão para a cobertura pleiteada no caso concreto.

(c) Legislação que fundamenta a decisão: número do artigo (da lei ou resolução) citado como fundamento nuclear para a decisão. Não se incluem aqui aqueles dispositivos sobre questões processuais ou sobre quaisquer elementos que apenas tangenciam o objeto principal da lide (por exemplo, fundamentação jurídica quanto à incidência de dano moral).

(d) Identificação da necessidade de internação: caso verificado que a cobertura pleiteada diz respeito a uma internação hospitalar, a célula é preenchida com "sim". Do contrário, atribui-se "não" como resposta.

(e) Casos em que se considerou a cláusula contratual abusiva ou nula: caso se verifique que a decisão considerou abusiva ou nula a cláusula que estabelece a limitação para a emergência médica, a célula deve ser preenchida com a resposta "sim". Do contrário, atribui-se "não" como resposta.

(f) Princípios relacionados ao mérito da questão: listagem dos princípios correlacionados ao ponto central da demanda (cobertura emergencial). Não deve ser registrado aqui o uso de princípios sobre direito processual ou dos princípios da proporcionalidade ou razoabilidade para o arbitramento de dano moral. Também não foram listados os princípios invocados pela operadora (e transcritos na decisão) e aqueles decorrentes de outros julgados (cuja ementa segue transcrita na decisão em exame).

(g) Observações: indicação se o acórdão é favorável (ou não) à aplicação da limitação de cobertura prevista pela Resolução CONSU n. 13/98 e anotação de quaisquer outros aspectos importantes não elencados acima. 


\section{Resultados}

Como será abordado com maior detalhamento a seguir, uma parte do resultado bruto dos tribunais de São Paulo, Rio de Janeiro e Minas Gerais foi submetida a uma filtragem com o descarte daqueles acórdãos que foram identificados como fora dos parâmetros desejados pela pesquisa ("Sem Análise de Mérito"). Assim, após a seleção da amostra, chegou-se a um total líquido de 88 acórdãos do TJ-SP, 56 acórdãos do TJ-RJ e 26 acórdãos do TJ-MG.

Mesmo nos casos em que a decisão não cita o procedimento pleiteado, foi possível identificar quando o objeto demandado na ação judicial é uma internação hospitalar. Aliás, esta situação é praticamente unânime nas três amostras: pleiteia-se internação hospitalar em 93\% dos acórdãos do TJ-SP e em 100\% dos casos provenientes dos tribunais do Rio de Janeiro e de Minas Gerais.

Foi encontrada grande dificuldade para a identificação das condições médicas relacionadas aos acórdãos estudados (principalmente naqueles julgados provenientes do Tribunal do Rio de Janeiro), uma vez que parte relevante dos casos estudados não faz qualquer menção ao procedimento médico, à patologia ou ao sintoma relacionado(a) ao caso concreto (seja na ementa, seja no inteiro teor). A despeito dessa limitação e mesmo considerando um grupo bastante heterogêneo de ocorrências, observou-se uma significativa repetição de situações ligadas a cirurgias do aparelho gastrointestinal ${ }^{29}: 9$ em um total de 88 casos do TJ-SP (10,2\%), 4 em um total de 56 casos do TJ-RJ (7,1\%) e 6 em 26 casos do Tribunal de Minas Gerais (23\%). As situações médicas que mais se repetiram em cada amostra foram: emergências obstétricas ${ }^{30}$ para São Paulo (15\%); complicações/infecções no aparelho respiratório ${ }^{31}$ (20\%) para Rio de Janeiro; e ocorrências cardiológicas ${ }^{32}$ para Minas Gerais (28\%).

Buscando conduzir uma exposição mais detalhada sobre os argumentos utilizados, cada parte enumerativa deste item será dedicada a sintetizar os pontos mais importantes que foram identificados nas decisões dos Tribunais de Justiça de SP, RJ e MG. Ao final, também será feito um exame de convergência entre o entendimento dos três tribunais estudados e a abordagem decisória do Superior Tribunal de Justiça (STJ) para o mesmo tema.

\footnotetext{
${ }^{29}$ Circunstâncias incluídas nesse grupo: cirurgia de apendicite; cirurgia de vesícula; cirurgia intestinal; cirurgia para correção de invaginação intestinal; diverticulite aguda perfurada; tratamento de hemorragia digestiva baixa; tratamento de infecção intestinal e desidratação; videolaparoscopia para quadro de colecistite aguda; obstrução intestinal; remoção de tumor no intestino.

${ }^{30}$ Incluem-se aqui, dentre outros: aborto espontâneo; complicações no processo gestacional; parto; gestação ectópica com laparotomia de urgência; tratamento cirúrgico de cisto ovariano.

${ }^{31}$ Incluem-se aqui: bronquiolite; insuficiência respiratória; pneumonia.

${ }^{32}$ Incluem-se aqui: cateterismo; cirurgia cardíaca; colocação de stent; angioplastia coronária; implantação de marca-passo; implantação de pontes de safena; infarto agudo do miocárdio; revascularização do miocárdio; arritmia cardíaca; insuficiência cardíaca.
} 


\section{Posição do TJ-SP}

De um total de 96 ocorrências estudadas para o TJ-SP, oito casos não entraram no mérito $^{33}$ sobre a aplicabilidade da CONSU n. 13/1998, e em 88 casos foi discutido o mérito.

Destas 88 decisões em que foi discutida a validade da CONSU n. 13/1998, em 61 delas o tribunal considerou inaplicável a limitação trazida pela norma regulatória aqui examinada ${ }^{34}$. Em sentido oposto, outros 27 casos foram decididos em favor da CONSU n. 13/1998, considerando-a legítima a gerar efeitos ${ }^{35}$.

\footnotetext{
${ }^{33}$ Número e classificação dos acórdãos: 0015884-23.2009.8.26.0562 - Embargos de Declaração (publicado em: 18/08/2011); 0017107-35.2008.8.26.0048 - Embargos de Declaração (publicado em:12/09/2011); 0083069-81.2010.8.26.0000 - Embargos de Declaração (publicado em: 24/09/2012); 024421593.2008.8.26.0100 - Embargos de Declaração (publicado em: 23/03/2011); 0040922-16.2005.8.26.0000 Agravo de Instrumento (publicado em: 30/08/2005); 0049404-82.2008.8.26.0602 Apelação (publicado em: 26/06/2012); 9015963-61.2001.8.26.0000 Agravo de Instrumento (publicado em: 12/12/2001); 017993525.2008.8.26.0000 Apelação (publicado em: 19/06/2012).

${ }^{34}$ Número e classificação dos acórdãos: 1043750-75.2013.8.26.0100 Apelação; 0000166-11.2014.8.26.0400 Apelação;0006856-42.2008.8.26.0505Apelação;0130805-86.2010.8.26.0100Apelação;0156825-51.2009.8.26.0100 Apelação; 0000727-73.2011.8.26.0001 Apelação; 0023476-24.2011.8.26.0506 Apelação; 000208153.2011.8.26.0060 Apelação; 0053020-35.2012.8.26.0114 Apelação; 0010003-39.2008.8.26.0291 Apelação; 0142617-68.2009.8.26.0001 Apelação; 0006782-53.2010.8.26.0590 Apelação; 9061483-63.2009.8.26.0000 Apelação; 0201760-45.2010.8.26.0100 Apelação; 0006836-40.2010.8.26.0001 Apelação; 000704564.2009.8.26.0576 Apelação; 0214968-24.2009.8.26.0006 Apelação; 9058653-27.2009.8.26.0000 Apelação; 0128008-06.2011.8.26.0100 Apelação; 0010054-66.2010.8.26.0554 Apelação; 0206936-24.2009.8.26.0008 Apelação; 9175412-74.2009.8.26.0000 Apelação; 0038556-72.2012.8.26.0577 Apelação; 925163687.2008.8.26.0000 Apelação; 0152277-85.2006.8.26.0100 Apelação; 9096964-24.2008.8.26.0000 Apelação; 0025600-65.2010.8.26.0004 Apelação; 0028921-77.2011.8.26.0003 Apelação; 9124475-94.2008.8.26.0000 Apelação; 9135652-21.2009.8.26.0000 Apelação; 0036103-81.2009.8.26.0554 Apelação; 000297196.2009.8.26.0048 Apelação; 0290497-67.2009.8.26.0000 Apelação; 0022291-60.2011.8.26.0114 Apelação; 9068718-52.2007.8.26.0000 Apelação; 0128267-15.2008.8.26.0000 Apelação; 0002952-36.2011.8.26.0011 Apelação ; 0348114-82.2009.8.26.0000 Apelação; 9252263-91.2008.8.26.0000 Apelação; 010144496.2011.8.26.0000 Agravo de Instrumento; 0057961-16.2011.8.26.0000 Agravo de Instrumento; 012839336.2006.8.26.0000 Apelação; 0229021-19.2009.8.26.0100 Apelação; 0128997-46.2010.8.26.0100 Apelação; 0161838-65.2008.8.26.0100 Apelação; 9131086-63.2008.8.26.0000 Apelação; 9146557-22.2008.8.26.0000 Apelação; 0012837-33.2007.8.26.0361 Apelação; 0441237-03.2010.8.26.0000 Agravo de Instrumento; 0127694-74.2008.8.26.0000 Apelação; 9097000-66.2008.8.26.0000 Apelação; 9070051-39.2007.8.26.0000 Apelação Sem Revisão; 9075342-64.2000.8.26.0000 Apelação Cível; 9087183-17.2004.8.26.0000 Apelação Com Revisão; 0072134-60.2002.8.26.0000 Apelação Com Revisão; 9102468-84.2003.8.26.0000 Apelação Com Revisão; 9224280-20.2008.8.26.0000 Apelação Com Revisão; 9249267-23.2008.8.26.0000 Apelação; 9045040-08.2007.8.26.0000 Agravo de Instrumento; 0285702-18.2009.8.26.0000 Embargos de Declaração; 0008747-17.2010.8.26.0477 Embargos de Declaração.

${ }^{35}$ Número e classificação dos acórdãos: 0118881-15.2009.8.26.0003 Embargos Infringentes; 017876504.2011.8.26.0100 Apelacão; 0039726-26.2009.8.26.0564 Apelação; 0039726-26.2009.8.26.0564 Apelação; 0113903-87.2012.8.26.0100 Apelação; 9109024-92.2009.8.26.0000 Apelação; 028152778.2009.8.26.0000 Apelação; 0118881-15.2009.8.26.0003 Apelação; 0019355-60.2010.8.26.0223 Apelação; 0129451-89.2011.8.26.0100 Apelação; 0129744-36.2009.8.26.0001 Apelação; 000453979.2011.8.26.0048 Apelação; 0191977-63.2009.8.26.0100 Apelação; 0029764-90.2010.8.26.0451 Apelação; 0415554-13.2009.8.26.0577 Apelação; 0008176-23.2010.8.26.0032 Apelação; 024421593.2008.8.26.0100 Apelação; 0284727-93.2009.8.26.0000 Apelação; 9110488-54.2009.8.26.0000 Apelação Com Revisão; 0284867-30.2009.8.26.0000 Apelação Com Revisão; 0339638-55.2009.8.26.0000 Apelação Com Revisão; 9095448-66.2008.8.26.0000 Apelação Com Revisão; 9250846-06.2008.8.26.0000 Apelação Com Revisão; 9282291-42.2008.8.26.0000 Apelação Com Revisão; 9214510-08.2005.8.26.0000 Embargos Infringentes; 9154132-23.2004.8.26.0000 Apelação Com Revisão; 9204949-28.2003.8.26.0000 Apelação Com Revisão.
} 
No tocante aos casos decididos em favor da norma regulatória, verificou-se que todos eles partiram da $6^{\mathrm{a}}$ Câmara Cível de Direito Privado, o que parece ser um posicionamento isolado deste grupo.

Na corrente que considera inaplicável a CONSU n. 13/1998 (61 acórdãos), a tese assumida é que a norma regulatória usurpa sua função regulamentar e limita um direito garantido pela Lei Federal 9.656/1998. Nesse sentido, 95\% dos acórdãos deste grupo ( 58 em 61) indicam que a cláusula redigida nos termos do ordenamento regulatório é nula ou abusiva ${ }^{36}$. Como dispositivos mais utilizados na fundamentação legal, figuram os artigos 35-C e 12 (e seus respectivos incisos), cuja enunciação foi verificada, respectivamente, em $73 \%$ e $74 \%$ dos 61 acórdãos. Também merece destaque o dispositivo sobre cláusula abusiva do Código de Defesa do Consumidor (artigo 51, inciso IV da Lei Federal n. 8.078/19907), citado em 21\% dos acórdãos deste grupo. Não se observou um uso significativo de princípios jurídicos na estrutura argumentativa desta corrente - quando presentes, estão citados em alguma ementa transcrita de outro julgado, e não no próprio texto da decisão.

$\mathrm{Na}$ extremidade oposta - a corrente representada pelo grupo de 27 acórdãos que admitem a limitação de cobertura prevista pela CONSU n. 13/1998 (6ª Câmara Cível) - funda-se na presunção de que a norma é suficientemente clara e de prévio conhecimento do consumidor. Ademais, enxergam que o comando normativo infralegal não sacrifica a lógica trazida pelo artigo da Lei Federal n. 9.656/1998, não havendo que se falar em "extrapolação do Poder Regulamentar". A seguir, alguns trechos que ilustram a linha interpretativa deste grupo:

Cláusula que não é abusiva, pois a restrição se apresenta clara e precisa, redigida com destaque e sem subterfúgio gramatical - Emergência e/ou urgência que também não favorecem os apelados, pela redação da Resolução CONSU n $13 / 98$ (da ANS) - Precedentes da Câmara. Apelação. Acórdão 017876504.2011.8.26.0100. Relator: Desembargador Percival Nogueira. Data de registro: 22/11/2012.

\footnotetext{
${ }^{36} \mathrm{Em}$ apenas três acórdãos não se considerou expressamente a abusividade ou inaplicabilidade do dispositivo contratual que impõe limitação de atendimento. Em duas decisões, embora considerando a cláusula válida, entendeu-se que sua interpretação deve ser favorável ao consumidor (artigo 47 do CDC) e não deve se sobrepor à vida do paciente - Acórdãos n. 0441237-03.2010.8.26.0000 (registro em: 11 de fevereiro de 2011) e 0012837-33.2007.8.26.0361 (registro em 02 de março de 2011). Em outro caso, considerou-se pouco transparente o critério de limitação de cobertura em cada local de atendimento e, desta forma, aplicou-se a interpretação mais favorável ao consumidor - 9102468-84.2003.8.26.0000 (registro em: 06 de julho de 2005). Forçoso reconhecer que todos, ainda que não declaradamente, obstruem a incidência da norma regulatória.

37“Art. 51. São nulas de pleno direito, entre outras, as cláusulas contratuais relativas ao fornecimento de produtos e serviços que: [...] IV - estabeleçam obrigações consideradas iníquas, abusivas, que coloquem o consumidor em desvantagem exagerada, ou sejam incompatíveis com a boa fé e a equidade". BRASIL. Lei Federal n. 8.078, de 11 de setembro de 1990. Dispõe sobre a proteção do consumidor e dá outras providências. Disponível em: <http://www.planalto. gov.br/ccivil_03/leis/L8078compilado.htm>. Acesso em: 28 abr. 2016.
} 
[...] destina-se aquela carência às hipóteses de preservação da vida, e, via de regra, de atendimento de pequenos acidentes (por exemplo, uma fratura simples, uma sutura rápida etc.), que não evoluam para a internação. Isso ocorrendo, cessa o dever de promover a assistência, caso ainda não completadas as demais carências.Embargos Infringentes. Acórdão 0118881-15.2009.8.26.0003. Relator: Desembargador Vito Guglielmi. Data de registro: 11/12/2012.

[...] é uma carência bastante limitada (ao contrário do que se imagina ...), destinada às hipóteses de preservação da vida e, via de regra, de atendimento de pequenos acidentes (p.ex. fratura simples, sutura rápida etc.), que não evoluam para internação. Tal ocorrendo, cessa o dever de promover financeiramente a assistência, se não completadas as demais carências, o que, como se viu, ocorreu na espécie (a carência para internação era de cento e oitenta dias). Também não se diga que tal cláusula de carência seria abusiva. Muito já se tem discutido a respeito nos pretórios, inclinando-se o entendimento desta Relatoria no sentido de se caracterizar a abusividade apenas quando mal redigida, confusa, omissa ou "escondida" (não redigida com o necessário destaque) a respectiva cláusula. Entendimento contrário importaria em desequilíbrio da equação econômico-financeira que norteia o contrato (somente ao Estado, por força de preceito constitucional, se pode exigir a prestação de serviços de saúde ilimitados), além de desrespeito à livre iniciativa e à força vinculante das obrigações (pacta sunt servanda). Apelação com Revisão. Acórdão 9154132-23.2004.8.26.0000. Relator: Desembargador Percival Nogueira. Data de registro: 09/08/2007.

Em síntese, a parte minoritária do TJ-SP considera que, quando bem redigida, a cláusula contratual encontra respaldo jurídico pela CONSU n. 13/1998 e tem a função de garantir o equilíbrio econômico-financeiro que norteia o contrato de assistência privada à saúde. Em 100\% deste grupo (27 ocorrências em 27 acórdãos), a decisão destaca os valores de livre iniciativa e da força vinculante dos contratos (pacta sunt servanda) e sustenta-se pela combinação entre o artigo 35-C da Lei Federal n. 9.656/1998 e os artigos $2^{\circ}$ ou $3^{\circ}$ da CONSU n. 13/1998.

\section{Posição do TJ-RJ}

Do total dos 63 julgados do TJ-RJ, sete casos não entraram no mérito ${ }^{38} \mathrm{da}$ aplicabilidade da norma regulatória. Nos 56 acórdãos restantes, mostra-se unânime

\footnotetext{
${ }^{38}$ Números e classificação dos acórdãos: 0014526-34.2014.8.19.0209- Apelação Cível; 003372529.2010.8.19.0000 - agravo de instrumento; 0040862-62.2010.8.19.0000 - agravo de instrumento; 0005224-65.2010.8.19.0000 - agravo de instrumento; 0002928-71.2005.8.19.0024- Apelação Cível; 0034276-50.2008.8.19.0203- Apelação Cível; 0076025-62.1994.8.19.0001- Apelação Cível.
} 
o entendimento quanto à inaplicabilidade da resolução por vício de legalidade, ou seja, em decorrência da extrapolação de sua função regulamentar ${ }^{39}$.

De forma semelhante ao TJ-SP, o tribunal fluminense é bem enfático ao concluir que a emergência não só abrange a parte ambulatorial, mas também contempla aqueles atendimentos em regime de internação hospitalar - ponto de onde se extrai o fundamento para a declaração de abusividade da cláusula e violação da boa-fé objetiva. No grupo de 56 acórdãos, os dispositivos da Lei Federal n. 9.656/1998 mais citados como fundamentação decisória são os artigos $35-\mathrm{C}(70 \%)$ e $12(68 \%)$.

Comparativamente, o TJ-RJ é o que mais incorpora dispositivos do CDC e princípios jurídicos no corpo de sua estrutura argumentativa. Observou-se um maior número de fundamentações lastreadas pelo dispositivo do artigo 51, inciso IV $(25 \%)$, seguindo-se do artigo $4^{\circ}$, inciso III $^{40}(29 \%)$ e do artigo $47^{41}$ $(16 \%)$ - todos do CDC. No tocante aos princípios, há forte destaque para o princípio da boa-fé (38\%), que figura muito acima do segundo e terceiro mais

\footnotetext{
${ }^{39}$ Números e classificação dos acórdãos: 0086889-96.2007.8.19.0004- Apelação Cível; 001283149.2009.8.19.0038-Apelação Cível; 0145171-63.2012.8.19.0001-Apelação Cível; 0271317-18.2013.8.19.0001Apelação Cível; 0016290-98.2013.8.19.0206- Apelação Cível; 0241427-34.2013.8.19.0001- Apelação Cível; 0028468-15.2013.8.19.0001- Apelação Cível; 0165282-05.2011.8.19.0001- Apelação Cível; 0998437-60.2011.8.19.0002- Apelação Cível; 0019382-28.2012.8.19.0042- Apelação Cível; 002025794.2012.8.19.0204-ApelaçãoCível;0351698-52.2009.8.19.0001-ApelaçãoCível;0096895-06.2009.8.19.0001Apelação Cível; 0025634-73.2012.8.19.0001- Apelação Cível; 0023512-84.2008.8.19.0209- Apelação Cível; 0143358-35.2011.8.19.0001- Apelação Cível; 0003188-85.2008.8.19.0205- Apelação Cível; 002282843.2009.8.19.0204-ApelaçãoCível;0169657-20.2009.8.19.0001-ApelaçãoCível; 0024424-47.2009.8.19.0209Apelação Cível; 0062101-66.2003.8.19.0001- Apelação Cível; 0012715-20.2006.8.19.0209- Apelação Cível; 0003357-26.2009.8.19.0209- Apelação Cível; 0017487-55.2008.8.19.0209- Apelação Cível; 001038521.2008.8.19.0002-Apelação Cível; 0008980-81.2007.8.19.0002-Apelação Cível;0036966-11.2010.8.19.0000 - agravo de instrumento; 0142629-77.2009.8.19.0001- Apelação Cível; 0004388-31.2006.8.19.0001- Apelação Cível; 0182766-04.2009.8.19.0001- Apelação Cível; 0086217-29.2009.8.19.0001- Apelação Cível; 0105434-63.2006.8.19.0001- Apelação Cível; 0021397-90.2008.8.19.0209- Apelação Cível; 001798991.2008.8.19.0209-Apelação Cível;0009396-07.2007.8.19.0210-Apelação Cível; 0026319-77.2008.8.19.0209Apelação Cível; 0155830-73.2008.8.19.0001- Apelação Cível; 0036377-50.2009.8.19.0001- Apelação Cível; 0215257-35.2007.8.19.0001- Apelação Cível; 0040502-69.2008.8.19.0042- Apelação Cível; 0006659-13.2006.8.19.0001- Apelação Cível; 0041897-62.2008.8.19.0021- Apelação Cível; 001810245.2008.8.19.0209-Apelação Cível; 0011951-97.2007.8.19.0209-Apelação Cível; 0122600-74.2007.8.19.0001Apelação Cível; 0005101-61.2006.8.19.0209- Apelação Cível; 0002187-87.2007.8.19.0209- Apelação Cível; 0028365-52.2006.8.19.0001- Apelação Cível; 0011831-66.2007.8.19.0205- Apelação Cível; 000464551.2005.8.19.0208-ApelaçãoCível;0127024-96.2006.8.19.0001-ApelaçãoCível; 0081829-88.2006.8.19.0001Apelação Cível; 0027829-41.2006.8.19.0001- Apelação Cível; 0007647-34.2006.8.19.0001- Apelação Cível; 0048972-23.2005.8.19.0001- Apelação Cível; 0003037-78.2006.8.19.0209- Apelação Cível.

40"Art. $4^{\circ} \mathrm{A}$ Política Nacional das Relações de Consumo tem por objetivo o atendimento das necessidades dos consumidores, o respeito à sua dignidade, saúde e segurança, a proteção de seus interesses econômicos, a melhoria da sua qualidade de vida, bem como a transparência e harmonia das relações de consumo, atendidos os seguintes princípios: [...] III - harmonização dos interesses dos participantes das relações de consumo e compatibilização da proteção do consumidor com a necessidade de desenvolvimento econômico e tecnológico, de modo a viabilizar os princípios nos quais se funda a ordem econômica (art. 170, da Constituição Federal), sempre com base na boa-fé e equilíbrio nas relações entre consumidores e fornecedores". BRASIL. Lei Federal n. 8.078, de 11 de setembro de 1990, cit.

${ }^{41}$ “Art. 47. As cláusulas contratuais serão interpretadas de maneira mais favorável ao consumidor”. BRASIL. Lei Federal n. 8.078, de 11 de setembro de 1990, cit.
} 
citados: princípio da transparência (14\%) e princípio da dignidade da pessoa humana (13\%).

Merece destaque a Ação Civil Pública ajuizada pelo Ministério Público do Rio de Janeiro em face de diversas operadoras e seguradoras de saúde, questionando a validade de cláusula contratual com a limitação de tempo de internação (Ação Civil Pública n. 2006.001.033570-5). Este precedente foi citado em votos de diferentes desembargadores e, por vezes, foi possível observar transcrições de sua ementa na fundamentação de outros acórdãos. Destaca-se abaixo um importante trecho extraído da decisão do TJ-RJ para a Ação Civil Pública em questão, no ponto em que discute a limitação de tempo prevista pela norma regulatória:

[...] Segundo o artigo 84, IV, da CRFB, os decretos e regulamentos têm seu âmbito de normatização restrito à fiel execução das leis; no entanto, ao impor a Resolução 13/98 limite de 12 horas para o atendimento aos segurados dos planos ambulatoriais e hospitalares, sob a responsabilidade de custeio das sociedades seguradoras, ataca diretamente não apenas a previsão expressa, e não limitada no tempo do artigo 12 da Lei $9.656 / 98$, que lhe é hierarquicamente superior, como a própria mens legis do diploma. De fato, que sentido haveria na contratação de plano de saúde se, nos casos mais graves de ameaça à incolumidade física dos segurados, estes apenas dispusessem de cobertura para um tratamento de 12 horas? O senso comum indica, sem muito esforço, que mais frequentemente do que não, acidentes e doenças que acometem o ser humano se caracterizam pela emergência ou urgência e faz-se necessário mais que meras doze horas para a plena recuperação do organismo. A saúde humana, sua manutenção, e especialmente sua reposição, são elementos caracterizados nuclearmente pela imprevisibilidade. Apelação 0028365-52.2006.8.19.0001. Relatora: Desembargadora Maria Augusta Vaz Monteiro de Figueiredo - 1 ${ }^{\text {a }}$ Câmara Cível. Data de publicação: 30/10/2008.

\section{Posição do TJ-MG}

Do total de 27 ocorrências estudadas para o TJ-MG, em um caso não se entrou no mérito ${ }^{42}$ e em 26 acórdãos foi discutido o mérito da aplicabilidade da CONSU n. 13/1998.

\footnotetext{
${ }^{42}$ Número do acórdão: Apelação Cível 1.0672.12.001872-2/001.
} 
Em todas as 26 decisões em que foi discutida a validade da CONSU n. 13/1998, o tribunal decidiu que a resolução é inaplicável por vício de legalidade em razão da extrapolação de sua função regulamentar ${ }^{43}$.

A fundamentação legal é bastante uniforme e a estrutura argumentativa dos acórdãos sempre se baseia no descumprimento do artigo 12, inciso $\mathrm{V}$ e/ou do artigo 35-C (e seus incisos) - ambos da Lei Federal n. 9.656/1998. Na maior parte dos casos, esses artigos são mencionados em conjunto $(84,6 \%)$ e, em poucas decisões, observou-se a citação de apenas um deles isoladamente (cerca de 7,7\% para cada artigo isolado). Os princípios mais citados são o princípio da boa-fé e o princípio da função social do contrato, cada um deles citados em 15\% dos acórdãos analisados.

\section{Exame de convergência entre o entendimento dos tribunais inferiores e a jurisprudência do Superior Tribunal de Justiça (STJ)}

Uma questão que pode passar desapercebida nos casos estudados é que o atrito entre o posicionamento judicial e a norma regulatória não decorre apenas da limitação de atendimento para as 12 primeiras horas. Há uma clara divergência interpretativa acerca do alcance procedimental daquilo que se considera ser o encerramento de um evento "emergencial".

Para a norma regulatória, salvo exceções pontuais ${ }^{44}$, encerra-se a urgência/emergência no momento em que forem garantidos os cuidados para manutenção e estabilização do quadro clínico e, consequentemente, o paciente receba alta ou "evolua" para uma necessária internação hospitalar. É o que parece explicar a idealização de um prazo de 12 horas para os beneficiários inelegíveis à internação hospitalar: seria uma espécie de "margem de tolerância".

Não obstante, consoante o entendimento apresentado por parte majoritária dos tribunais estudados, a cobertura deve abranger todos os procedimentos inerentes ao tratamento imediato da condição médica acometida pelo usuário, o que significa dizer que engloba toda a cadeia de procedimentos, inclusive aqueles de internação hospitalar - não havendo que se falar em imposição de limites aos

\footnotetext{
${ }^{43}$ Número dos acórdãos: Apelação Cível 1.0024.13.021018-0/001; Apelação Cível 1.0024.12.2837511/001; Apelação Cível 1.0223.12.026227-2/001; Apelação Cível 1.0702.10.055413-9/001; Apelação Cível 1.0024.10.018312-8/001; Apelação Cível 1.0024.09.571791-4/001; Apelação Cível 1.0701.07.1974680/001; Apelação Cível 1.0518.08.147790-4/001; Apelação Cível 1.0024.06.026553-5/001; Apelação Cível 1.0024.06.985453-7/001; Apelação Cível 1.0701.08.216448-7/001; Apelação Cível 1.0105.07.2381392/001; Apelação Cível 1.0701.07.202456-8/001; Apelação Cível 1.0701.05.133166-1/001; Apelação Cível 1.0024.06.932370-7/001; Apelação Cível 1.0024.06.033190-7/001; Apelação Cível 1.0024.06.2824131/001; Apelação Cível 2.0000.00.491731-9/000; Apelação Cível 2.0000.00.496307-3/000; Apelação Cível 1.0223.01.059566-6/001; Agravo de Instrumento 1.0145.05.280859-2/001; Apelação Cível 2.0000.00.515629-8/000; Apelação Cível 2.0000.00.431241-2/000; Apelação Cível 2.0000.00.4051421/000; Apelação Cível 2.0000.00.406899-9/000; Apelação Cível 2.0000.00.358619-2/000.

${ }^{44}$ Cobertura de urgências decorrentes de acidentes pessoais em planos de segmentação "Hospitalar" e qualquer cobertura de urgência e emergência para planos na segmentação "Referência”.
} 
cuidados hospitalares que se façam necessários após a prestação dos atendimentos iniciais em pronto-socorro.

É imperioso destacar que o Superior Tribunal de Justiça não penetra no exame de provas já apreciadas pelos tribunais inferiores, por força da Súmula STJ n. $7^{45}$. Nesse sentido, só se cogitaria a reversão da construção jurisprudencial edificada pelos tribunais de São Paulo, Rio de Janeiro e Minas Gerais caso o entendimento da Corte Superior admitisse a fragmentação dos cuidados de emergência em duas diferentes etapas (ambulatorial e hospitalar).

Este, entretanto, não é o entendimento do STJ. Conforme já consolidado pela Súmula n. 302: “[...] o período de carência contratualmente estipulado em contratos de seguro saúde não prevalece em situações emergenciais".

No tocante ao alcance do que se considera para a terminologia "situações emergenciais" descrita na súmula, é importante destacar que o STJ, em sentido contrário ao grupo minoritário da jurisprudência aqui revisada ( $6^{\mathrm{a}}$ Câmara Cível de São Paulo), sequer ventila sobre a hipótese de uma faixa divisória na qual se encerra a responsabilidade da operadora assim que o atendimento evolui para a etapa de internação em leito hospitalar ${ }^{46}$.

\section{Discussão}

A incursão empírica desempenhada pelo presente trabalho deu especial destaque ao mapeamento dos diferentes argumentos adotados pelos tribunais estudados quanto à aplicabilidade da norma regulatória.

Como já mencionado, optou-se por um grupo de palavras-chave que produzisse um resultado menor e mais sensível. Assim, embora exista uma limitação quanto à pretensão de mapear todo o universo de acórdãos sobre emergências médicas questionadas nos três tribunais, a amostra obtida permite um resultado conclusivo mais consistente sobre os fundamentos legais e principiológicos que

\footnotetext{
45“Súmula 7: A pretensão de simples reexame de provas não enseja Recurso Especial”. SUPERIOR TRIBUNAL DE JUSTIÇA. Disponível em: <http://www.stj.jus.br/docs_internet/VerbetesSTJ_asc.pdf>. Acesso em: 28 abr. 2016.

${ }^{46}$ Para citar alguns deles: AgRg no AREsp 110818/RS, Rel. Ministro João Otávio De Noronha, Terceira Turma, julgado em 06/08/2013, DJe 19/08/2013; AgRg no AREsp 327767/CE, Rel. Ministro Sidnei Beneti, Terceira Turma, julgado em 25/06/2013, DJe 01/08/2013; AgRg no AREsp 213169/RS, Rel. Ministro LUIS Felipe Salomão, Quarta Turma, julgado em 04/10/2012, DJe 11/10/2012; REsp 1243632/ RS, Rel. Ministro Paulo De Tarso Sanseverino, Terceira Turma, julgado em 11/09/2012, DJe 17/09/2012; AgRg no Ag 845103/SP, Rel. Ministro Ricardo Villas Bôas Cueva, Terceira Turma, julgado em 17/04/2012, DJe 23/04/2012; AgRg no REsp 929893/PR, Rel. Ministro Raul Araújo, Quarta Turma, julgado em 15/03/2012, DJe 13/04/2012; REsp 1401390/MT (decisão monocrática), Rel. Ministro Marco Buzzi, julgado em 28/08/2013, DJe 04/09/2013; AREsp 365096/RS (decisão monocrática), Rel. Ministra Nancy Andrighi, julgado em 21/08/2013, DJe 28/08/2013; AREsp 159310/SP (decisão monocrática), Rel. Ministro Antonio Carlos Ferreira, julgado em 13/12/2012, DJe 18/02/2013; AREsp 77435/DF (decisão monocrática), Rel. Ministra Maria Isabel Gallotti, julgado em 10/12/2012, DJe 12/12/2012.
} 
sustentam a interpretação judicial quanto à aplicabilidade ou inaplicabilidade da Resolução CONSU n. 13/1998.

Quanto ao alcance procedimental da emergência, o posicionamento majoritário dos três tribunais estudados é no sentido de haver obrigatoriedade para a cobertura de toda a extensão do procedimento emergencial, sendo descabida a linha divisória entre o atendimento ambulatorial inicial e sua posterior evolução para internação. Este, aliás, é um fator relevante que explica a opção pelo sistema judiciário, feita por usuários nesses casos: os pedidos de internação integram quase a totalidade dos acórdãos aqui examinados.

Ao interpretar o sentido de "urgência" e "emergência" como um ato contínuo entre as segmentações ambulatorial e hospitalar, derroga-se a demarcação idealizada pela norma regulatória e prevalece a lógica adotada pelo Poder Judiciário. Para tanto, a maior parte das decisões tem como fundamento os dispositivos encabeçados pelos artigos 12 e 35-C da Lei Federal n. 9.656/1998) e baseia-se na tese de que a resolução atacada extrapola seu poder regulamentar. Também merece destaque a importância dada ao CDC e ao princípio da boa-fé na argumentação decisória do TJ-RJ.

Embora seja admissível algum constrangimento da regra legal (aberta) por seu respectivo instrumento regulamentador, a regulamentação deve manter-se dentro das balizas textuais previstas pelo dispositivo legal. Nesta ilação, o fundamento decisório para a conclusão dos tribunais pela ilegalidade parece estar pautado em um parâmetro de equivalência entre o teor de ambos os instrumentos normativos (legal e infralegal), cujo limite entre "regulamentar" e "violar" o dispositivo encabeçado pela lei perpassa por um inevitável critério de razoabilidade por equivalência ${ }^{47}$.

Vale destacar que o afastamento da norma regulatória é operado de maneira incidental e dirige-se à cláusula contratual ou ao ato concreto da operadora que se ampara na Resolução CONSU. Nesse sentido, o argumento de nulidade (ou abusividade) da cláusula que encabeça a limitação de cobertura é o principal instrumento para a viabilização desse bloqueio.

É imperioso ressaltar que a aplicabilidade da norma regulatória já foi discutida em âmbito federal no bojo da Ação Civil Pública n. 2009.61.00.002894-4, tramitada e julgada na 6a Vara Federal da subseção judiciária de São Paulo. Na ocasião, o Ministério Público Federal requeria a declaração de ilegalidade dos artigos $2^{\circ}, 3^{\circ}$ e $6^{\circ}$ da CONSU n. 13/1998 e a condenação da ANS para que editasse nova resolução corrigindo os problemas apontados pelo parquet. Na sentença, publicada em

\footnotetext{
${ }^{47}$ Nas palavras de Humberto Ávila, trata-se do critério que "[...] exige uma relação de equivalência entre a medida adotada e o critério que a dimensiona" (AVILA, Humberto. Teoria dos princípios: da definição à aplicação dos princípios jurídicos. 16. ed. São Paulo: Malheiros Ed., 2015. p. 200). Nesse sentido, a desproporção entre a medida restritiva infralegal e o critério dimensionado em Lei pode indicar algum tipo de violação a este dever de equivalência.
} 
8 de julho de $2010^{48}$, o juiz federal indeferiu ambos os pedidos. Discordou do pedido para a edição de uma nova norma por entender que tal medida se caracterizaria como invasão de uma seara que compete institucionalmente à autarquia. No tocante à declaração de ilegalidade, a sentença foi deferente à discricionariedade técnica da autarquia e examinou exclusivamente alguns aspectos formais de competência, conforme se infere do trecho abaixo transcrito:

As condições dispostas nos artigos 2, 3 e 6 da Resolução CONSU n. 13/98 estão em conformidade com o sistema constitucional de proteção ao consumidor. Enfim, a Administração Pública possui prerrogativas próprias da supremacia do interesse público, presumindo-se válidos os seus atos. A oportunidade, a conveniência e o próprio mérito do ato administrativo discricionário regulamentar não poderão desprezar os princípios da Constituição, que funcionam como critério objetivo de toda a Administração Pública. [...] Inexistente qualquer vício formal ou material nos artigos 2, 3 e 6 da Resolução CONSU n. 13/98, colocados que estão em harmonia com os princípios constitucionais e com a legislação de regência. DISPOSITIVO. Ante o exposto, JULGO IMPROCEDENTE o pedido e extingo o processo com resolução de mérito, nos termo do artigo 269, I, do CPC.

Percebe-se, assim, certa incoerência entre os posicionamentos do subsistema judiciário: embora a Justiça Federal tenha reconhecido a legitimidade da norma, os tribunais estaduais declaram nulas aquelas cláusulas que instrumentalizam o disposto pela Resolução CONSU. Como resultado, é produzido um controle judicial "indireto", oblíquo, no qual a norma regulatória, embora não expurgada do ordenamento, é sistematicamente desconsiderada por força das decisões da Justiça Estadual.

Ademais, tratando-se de um direito fundamental extremamente sensível (direito à vida), é previsível que exista uma maior vinculação à juridicidade ${ }^{49}$ quando identificada pelo magistrado, em cognição sumária (na maior parte dos casos), alguma restrição nesse sentido.

Desta feita, partindo-se da premissa de que as operadoras de planos de saúde pautam-se no paradigma regulatório para redigir seus contratos e guiar seus procedimentos de autorização de coberturas médicas, a permanência desse atrito institucional cria um incentivo patológico à judicialização dos casos que envolvam negativas de cobertura para urgência e emergência. Isso leva a uma inevitável

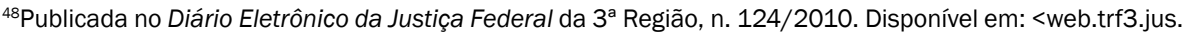
br/diario/Consulta/BaixarPdf/2843>. Acesso em: 28 fev. 2016.

${ }^{49}$ Tomada de decisão nesse sentido pode ser identificada no modelo teórico de vinculação à juridicidade proposto por Gustavo Binenbojm em sua obra “Uma Teoria do Direito Administrativo". BINENBOJM, Gustavo. Uma teoria do direito administrativo: direitos fundamentais, democracia e constitucionalização. Rio de Janeiro: Renovar, 2006. p. 316.
} 
insegurança jurídica, além do aumento dos custos administrativos e seus consequentes impactos no preço final do produto.

Analisando-se pragmaticamente a questão e reconhecendo-se que a normatização infralegal tem sido espancada pela maioria dos tribunais no decorrer dos últimos anos, resta saber se existem evidências satisfatórias que possam advogar em favor da norma atacada - no sentido de demonstrar a plausibilidade da regra tida como desarrazoada e demonstrar a inviabilidade de outras possíveis medidas alternativas (franquias, por exemplo) ${ }^{50}$. Inexistindo base empírica e razões consistentes para insistir na permanência da Resolução CONSU, talvez seja a hora de reavaliar o papel desempenhado atualmente pelo instrumento normativo e discutir formas para minimizar tais litígios.

Pelo exposto, mostra-se de suma importância que a agência reguladora faça uma reanálise do paradigma regulatório e discuta (com o setor e com a sociedade) quais seriam as alternativas viáveis para a operacionalização do acesso à cobertura emergencial em substituição ao modelo legalmente previsto.

Paralelamente, algumas ferramentas podem ser usadas pelo Poder Judiciário para uma melhor compreensão dos casos concretos, a exemplo dos Núcleos de Apoio Técnico (NAT) - que assessoram tecnicamente o juiz em casos concretos envolvendo coberturas médicas ${ }^{51}$. Obviamente, para que esse modelo funcione, a indicação técnica precisa ser levada a sério pela fundamentação da sentença ${ }^{52}$.

Por fim, no plano interinstitucional, é necessário discutir a incoerência existente entre as normas do CFM e ANS, bem como promover maior diálogo e proximidade técnica entre a ANS e o Poder Judiciário, com o fito de uniformizar o tratamento a ser adotado nesses casos.

\footnotetext{
${ }^{50}$ Embora a sentença publicada em 08 de julho de 2010 nos autos da Ação Civil Pública n. 2009.61.00.0028944, em curso no Tribunal Regional Federal da $3^{a}$ Região, tenha citado existir uma "[...] nota da Gerência-Geral Técnico-Assistencial dos Produtos - GGTAP da ANS, com esclarecimentos sobre os resultados do grupo de trabalho formado para discussão e aperfeiçoamento da Resolução CONSU n 13/98", nenhum documento nesse sentido foi disponibilizado publicamente para consulta a partir do sítio eletrônico da agência reguladora (AGÊNCIA NACIONAL DE SAÚDE SUPLEMENTAR - ANS (Brasil). Disponível em: <http://www. ans.gov.br>).

${ }^{51}$ Importante destacar que a adoção de assessoria técnica para apoio judicial em demandas de planos de saúde foi alvo de recente denúncia do IDEC dirigida ao NAT criado para demandas judiciais envolvendo planos de saúde no Tribunal de Justiça de São Paulo, por suspeita de captura deste segmento por agentes econômicos alinhados às operadoras de planos de saúde. (IDEC lança manifesto contra influência de planos de saúde na Justiça. Disponível em: <http://www.idec.org.br/o-idec/sala-de-imprensa/release/ idec-lanca-manifesto-contra-influencia-de-planos-de-saude-na-justica>).

${ }^{52}$ Em sua tese de doutorado, Miriam V. da Silva examinou a atuação do Núcleo de Apoio Técnico no Tribunal de Justiça do Rio de Janeiro (litígios sobre saúde pública) e verificou que, em grande parte dos julgados, a indicação técnica não era incorporada à fundamentação da sentença. SILVA, Miriam Ventura da. 0 processo decisório judicial e a assessoria técnica: a argumentação jurídica e médico-sanitária na garantia do direito à assistência terapêutica no Sistema Único de Saúde. Tese (Doutorado) - Escola Nacional de Saúde Pública Sergio Arouca, Rio de Janeiro, 2012.
} 


\section{Considerações finais}

O presente trabalho buscou identificar o grau de deferência judicial à Resolução CONSU n. 13/1998 (norma regulatória para urgências e emergências em planos de saúde) e verificar quais são os fundamentos adotados pelos acórdãos dos Tribunais de Justiça de São Paulo, Rio de Janeiro e Minas Gerais - três estados que, juntos, representam uma fatia expressiva do total de beneficiários de planos de saúde no Brasil.

Com base nas evidências encontradas, verificou-se uma flagrante colisão entre as decisões desses tribunais e a razão adotada pela norma regulatória atualmente em vigor (CONSU n. 13/1998), indicando um atrito interinstitucional nesse sentido.

Como medidas aptas à resolução do problema, além da necessária harmonia na interface entre ANS e Poder Judiciário, percebe-se a necessidade de uma norma regulatória que possa regulamentar, de maneira mais simples e judicialmente crível, o acesso às coberturas de urgência e emergência em planos de saúde.

\section{Referências}

AGÊNCIA NACIONAL DE SAÚDE SUPLEMENTAR - ANS (Brasil). Caderno de Informação de Saúde Suplementar: beneficiários, operadoras e planos. Agência Nacional de Saúde Suplementar, set. 2014.

AGÊNCIA NACIONAL DE SAÚDE SUPLEMENTAR - ANS (Brasil). Disponível em: <http:// www.ans.gov.br>.

ALVES, Danielle C.; BAHIA, Lígia; BARROSO, André F. O papel da Justiça nos planos e seguros de saúde no Brasil. Cad. Saúde Pública, Rio de Janeiro, 25, n. 2, p. 279-290, fev. 2009. Disponível em: $<$ http://www.scielo.br/pdf/csp/v25n2/06.pdf>.http://dx.doi.org/10.1590/S0102-311X2009000200006.

AVILA, Humberto. Teoria dos princípios: da definição à aplicação dos princípios jurídicos. 16. ed. São Paulo: Malheiros Ed., 2015.

BINENBOJM, Gustavo. Uma teoria do direito administrativo: direitos fundamentais, democracia e constitucionalização. Rio de Janeiro: Renovar, 2006.

CARLINI. Angélica Lucia. Judicialização da Saúde Pública no Brasil. In: CARNEIRO, Luiz Augusto (Coord.). Planos de saúde: aspectos jurídicos e econômicos. Rio de Janeiro: Forense, 2012.

DAHINTEN, Bernardo F. Planos de saúde e a proteção dos consumidores: a problemática dos casos de urgência/emergência. Revista Síntese Direito Empresarial, v. 30, p. 131-171, 2013.

DALLARI, Sueli G. Aspectos particulares da chamada judicialização da saúde. Revista de Direito Sanitário, São Paulo, v. 14, n. 1, p. 77-81, mar./jun. 2013. Disponível em: <http://www.revistas.usp. br/rdisan/article/view/56624/59641>. http://dx.doi.org/10.11606/issn.2316-9044.v14i1p77-81.

FIGUEIREDO, Leonardo Vizeu. Curso de direito em saúde suplementar: manual jurídico de planos e seguros de saúde. São Paulo: MP Ed., 2006. 
IDEC lança manifesto contra influência de planos de saúde na Justiça. Disponível em: <http:// www.idec.org.br/o-idec/sala-de-imprensa/release/idec-lanca-manifesto-contra-influenciade-planos-de-saude-na-justica $>$.

RIBEIRO, Rodrigo M. O controle judicial sobre as cláusulas de carência nos planos de saúde. 2009. Dissertação (Mestrado em Direito) - Faculdade de Direito da Universidade Candido Mendes, 2009.

SCHEFFER, Mário. Os planos de saúde nos tribunais: uma análise das ações judiciais movidas por clientes de planos de saúde, relacionadas à negação de coberturas assistenciais no Estado de São Paulo. 2006. Dissertação (Mestrado) - Faculdade de Medicina, Universidade de São Paulo, São Paulo, 2006.

SCHULMAN, Gabriel. Planos de saúde: saúde e contrato na contemporaneidade. Rio de Janeiro: Renovar, 2009.

SILVA, Miriam Ventura da. O processo decisório judicial e a assessoria técnica: a argumentação jurídica e médico-sanitária na garantia do direito à assistência terapêutica no Sistema Único de Saúde. Tese (Doutorado) - Escola Nacional de Saúde Pública Sergio Arouca, Rio de Janeiro, 2012.

SOUZA, C.C. et al. Classificação de risco em pronto-socorro: concordância entre um protocolo institucional brasileiro e Manchester. Rev. Latino-Am. Enfermagem [Internet], v. 19, n. 1, jan./fev 2011. Disponível em: <http://www.eerp.usp.br/rlae>. Acesso em: 13 abr. 2015. http://dx.doi.org/10.1590/S0104-11692011000100005.

SOUZA, M.H.S.C. et al. A intervenção do Poder Judiciário no setor de saúde suplementar - tutelas antecipadas como instrumento de garantia da assistência à saúde no Brasil. Divulgação em Saúde para Debate, Rio de Janeiro, n. 37, p. 44-60, jan. 2007. Disponível em: <http://abresbrasil.org. br/sites/default/files/poder_judiciario_bahia.pdf. Acesso: 01 mar. 2016.

SUPERIOR TRIBUNAL DE JUSTIÇA - STJ. Disponível em: <http://www.stj.jus.br>.

TRETTEL, Daniela B. Planos de saúde na Justiça: o direito à saúde está sendo efetivado? Estudo do posicionamento dos Tribunais Superiores na análise dos conflitos entre usuários e operadoras de planos de saúde. 2009. Dissertação (Mestrado) - Faculdade de Direito, Universidade de São Paulo, São Paulo, 2009.

Bruno Araujo Ramalho - Mestrando em Direito da Regulação pela Fundação Getúlio Vargas do Rio de Janeiro; graduado em Odontologia pela Universidade de São Paulo e em Direito pela Universidade Federal do Estado do Rio de Janeiro. Rio de Janeiro/RJ, Brasil. E-mail: brunrama@hotmail.com. 